regarded as the most reliable solvent extraction system for the recovery of uranium and plutonium from irradiated fuels. The degree to which this system is capable of technical improvement is now largely limited to ways in which the effluents of moderate radioactivity can be reduced in volume, for example, by using only one cycle, or be made capable of being evaporated to small bulk: in papers concerned with the latter aim, the results of research on the substitution of ferrous sulphamate by uranium (IV) nitrate as the reducing agent for the reaction plutonium (IV) $\rightarrow$ plutonium (III) were described. Otherwise, as was brought out in the contribution by Dr. $R$. Rometsch, the research director of Eurochemic, the main load that now falls on a research and development team is concerned with the problems involved in 'decladding' the wide variety of fuel elements used in Western European reactors and in bringing their contained fuel into solution of such a composition as to be suitable for the recovery of the fissile elements by solvent extraction.

There is now little work being done on ion exchangers for reprocessing: in the period 1950-60 they were developed and sometimes installed for the final purification of plutonium and uranium-233. The present tendency is to establish for these purification steps a solvent extraction process using a tertiary (or quaternary) amine, in a suitable organic diluent. The results from several laboratories on amine systems indicate that sufficient knowledge has already been accumulated for an amine-cycle to be capable of being successfully applied for this purpose. The two advantages of an amine, compared with the conventional tributylphosphate, for this particular purification-cycle consists in the better decontamination from uranium, and the greater reduction in the volume of the plutonium nitrate stream that the amine can provide.

Although the symposium dealt mainly with aqueous methods, there was a review by Dr. M. D'Hont (Nuclear Energy Centre, Mol, Belgium) on the alternatives, for example, reprocessing by melt refining or by fractional volatilization from halide systems. It is noticeable that these and similar non-aqueous methods, though a popular field for research at the time of the Geneva Conferences of 1955 and 1958, are losing favour. Their development costs seem likely to be prohibitive for any purpose other than an established fuel-cycle operating on a large number of reactors.
The final session was devoted to a discussion on the future role of reprocessing in fuel-cycles. It was introduced by Dr. F. L. Culler (Oak Ridge National Laboratory), who quoted his investigation on a scheme for the distillative purification of sea-water using, as a source of power, very large reactors (each of 8,700-MW thermal) fuelled with natural uranium, and cooled and moderated with heavy water: the lowness of the reprocessing cost (calculated to be about 4 dollars/kg of uranium) for the fuel-cycle concerned was primarily due to its large throughput (about 10 tons of uranium per day). This illustrated the important point that the throughput of a plant can influence costs to a greater degree than possible savings from improved technology. In the discussion which followed, two points of particular interest emerged. First, in the early stages of the expansion of the nuclear reactor industry, storage of irradiated fuels until such time as adequate quantities have accumulated to feed a large reprocessing plant may be preferable, on economic grounds, to the proliferation of many small plants: it would follow as a corollary of this policy, that the number of teams engaged on reprocessing research and development that should support such reprocessing would be relatively few in number. Secondly, for large reprocessing plants to be generally accepted, the problems in the transport of irradiated fuel both by water and on land must be overcome: these problems can be particularly severe where international boundaries have to be crossed.

About 100 persons drawn from fifteen countries as well as from the International Atomic Energy Agency and from Euratom attended the symposium, in addition to the forty scientists and technologists from Eurochemic. The meeting provided the first large gathering of the reprocessing experts of Western Europe and it was appropriate that the delegates could see at Mol the emergence of the Eurochemic plant. Dr. T. J. Barendregt and the others responsible under Dr. E. Pohland, the director-general of Eurochemic, for this plant have had to overcome many problems, new in plant construction, due to the components being supplied by one or other of the various countries which participate in Eurochemic. The plant represents a pioneering effort, new in Europe, from which benefits should accrue to many future co-operative enterprises.

J. M. Fletcher

\title{
FLOW STUDY OF POLYMER MELTS USING THE INSTRON RHEOMETER
}

\begin{abstract}
A $\mathrm{T}$ the meeting of the Cambridge Rheology Club held on March 4, Mr. G. G. Zahler (Instron, Ltd.) spoke on "Flow Study of Polymer Melts using the Instron Rheometer". First, he briefly discussed general flowcharacteristics of polymer melts showing that temperature, speed of flow and stress measurement should be accurately controlled, instrument geometry must be accurate and accessible. A rheometer must cover shear rates from at least 1 to 10,000 reciprocal seconds in order to simulate normal processing conditions from compression moulding to injection moulding.

The Instron rheometer, which is an extrusion type and was originally designed by Monsanto Chemicals (United States), is driven by an Instron model $T T$ - $C$ tensile testing machine. This machine covers load ranges from $2 \mathrm{~g}$ to $10,000 \mathrm{lb}$., using strain-gauge load cells, to an accuracy of 0.5 per cent on all ranges. Speeds are governed by a synchronous motor and positional servo-system, being instantly selectable through pushbuttons over a range of 10,000 to 1 .
\end{abstract}

The extrusion assembly consists of a barrel surrounded by four heaters connected to a controller giving proportional, integral and differential control from $10^{\circ} \mathrm{C}$ above ambient to $340^{\circ} \mathrm{C}$ within a limit of error of $\pm 0.5^{\circ} \mathrm{C}$. Capillaries of different diameters, lengths and entrance angles are inserted into the lower end of the barrel. A plunger is forced through the barrel by the moving crosshead of the tensile testing machine, the load on the plunger is recorded automatically by the load cell on a strip chart recorder. Tests over wide ranges of speed may be earried with one barrel loading. As plunger speed is known, plunger load is measured and dimensions of the extrusion assembly have been accurately determined, shear rate and shear stress can be readily calculated or read directly from nomo. graphs.

Mr. Zahler discussed possible errors such as due to the capillary aspect ratio, plunger friction force, fluid compressibility and temperature rise along the capillary, etc. $\mathrm{He}$ showed that all these effects were either negligible or could be easily corrected.

It was suggested that it is possible to measure the dynamic shear modulus (for visco-elastic flow) by steadystate flow in the capillary rheometer. This theory was substantiated by results obtained experimentally. Another parameter that can be measured is the activation 
energy of viscous flow. Rheopectic and thixotropic characteristics of materials can also be investigated.

The next meeting of the club will be held on October 28 at the Technological Research Station, Spillers, Ltd.,
Station Road, Cambridge, when Dr. J. H. C. Vernon (Ministry of Aviation) will speak on "The Rheology of Solid Propellants for Rocket Motors".

\section{E. Mary Nicholas}

\section{THE AUSTRALIAN ATOMIC ENERGY COMMISSION}

$\mathrm{T}$ HE tenth annual report of the Australian Atomic Energy Commission covers the year ended June 30, 1962 , in which the expenditure was $£ 2,803,787$ and capital expenditure $£ 905,275$. Revenue from sales, including lease of reactor space, was $£ 83,858$, an increase of $£ 28,615$ for the year. The cost of the exploration for uranium carried out by the Bureau of Mineral Resources and by Territory Enterprises Pty. Ltd., was $£ 194,000$.

On March 23, 1962, two major new buildings were opened by the Prime Minister, the Rt. Hon. R. G. Menzies. One was the Reactor Physics Building, housing the lowpower research reactor Moata, and the other the building devoted to Radiation Biology and Health Physics. The Hifar Experimental Building, a new Low-Level Radiochemistry Building, and extensions to the Isotope Handling Building, also were completed during the period under review. In a separate suite at the rear of the main block of the Radiochemistry Building is housed the total-body monitor, the radiation detector of which consists of a large scintillation crystal ( 8 in. diameter and 4 in. thick) of sodium iodide, suspended over the abdomen of the subject seated in a reclining chair. Two heavily shielded rooms with facilities for the irradiation of animals or biological specimens form part of the ground-floor of the building. One room contains a 10-c. cæsium-137 source for low dose-rate exposures and the other a $250-\mathrm{kV}$ $X$-ray plant for the delivery of doses of much higher levels.

The reactor research programme was mainly concentrated on the feasibility study of a high-temperature gas-cooled reactor, in which the fuel is dispersed in the moderator. Both beryllium metal and beryllium oxide have been investigated as moderators, with carbon dioxide as coolant. Most work has been done on the metal system, but because of the poor economics of the fuelcycle and the temperature limitations of the metal fucl, the oxide or ceramic system is now receiving greater consideration. The beryllium oxide moderated, allceramic fuel reactor seems to hold promise of some long-term advantage and it is believed that, provided certain design problems can be satisfactorily solved, a beryllium oxide based, high-temperature gas-cooled reactor should yield lower plant and equipment costs than most other gas-cooled systems. It would appear that with steels at present available the maximum temperature of the carbon dioxide coolant would be about $750^{\circ} \mathrm{C}$, which is a considerable advance on British gas. cooled stations of present design. To assess the value of the proposed type of reactor as a power producer, a design study for a power plant of net electrical output of $300 \mathrm{MW}$ has been started. The most difficult mechanical engineering problem involved is the production of the all-ceramic core of the reactor for as yet nobody has made any serious attempt to produce a satisfactory core based on beryllium oxide for power-station reactors. Several fuel cycles aro boing considered, with most attention being directed to the uranium-233, thorium, beryllium system, but because of lower initial cost and greater availability of fuel the plutonium-enriched, natural uranium cycle may be preferred for Australia.

In the annual report for 1961 , reference was made to the investigation being carried out on the compatibility

* Commonwealth of Australia. Tenth Annual Report of the Australian Atomic Energy Commission for the year ended 30th June 1962. Pp. 88. (Coogee, N.S.W.: Australian Atomic Energy Commission, 1962.) of steels with carbon dioxide. This is now essentially complete. Carbon steels, low alloy steels, and stainless steels have been studied at high temperatures and pressures, and for various moisture contents of the gas, and firm recommendations can now be made for the most satisfactory materials for use in the temperature range $400^{\circ}-750^{\circ} \mathrm{C}$ in the various parts of the gas circuit of a reactor. At the Lucas Heights Research Establishment some research on semi-conductor radiation detectors has been carried out. Silicon-surface barrier counters can now be produced quickly and economically, and their applications to $\alpha$-particle spectrometry and for scanning neutron flux are being studied. Radiation standards at the microcurie level for cobalt-60, gold-198, sodium-24, iridium-131, antimony-124 and phosphorus-32 have been developed and intercomparisons with standards of other laboratories are to be undertaken.

For neutron diffraction experiments, there will shortly be available. attached to the reactor Hifar, two powder spectrometers, two single crystal spectrometers, and one long-wave-length spectrometer. The spectrometers were all designed and built at the Lucas Heights Establishment, and will bo of use to the university groups from Western Australia who are interested in the positions of hydrogen atoms in organic crystals, and from the University of New South Wales who are investigating the defect structure of titanium-zirconium-oxygen alloys, the structure of inorganic crystals containing hydrogen and the structure of magnetic transition-metal alloys. The physics division is now operating a neutron time-of-flight spectrometer and a second one is in the design stage. They are to be used for the measurement of the distribution of neutron energies within reactor cores.

There are well-established facilities for the production, handling and dispatch of radioisotopes at the Lucas Heights Establishment, and the annual demand for those produced at the Establishment has increased four-fold. Short-lived isotopes, including sodium-24, potassium-42, copper-64 and gold-198, which are valuable in medical work and industrial investigations, were supplied for the first time. The first cobalt-60 was removed from the reactor Hifar during September 1961, after approximately 320 days irradiation. Eighty-eight per cent of the product had a radioactivity of more than $50 \mathrm{c}$. per gram, with a maximum of $105 \mathrm{c}$. per gram. 2,600 c. of the $8,270 \mathrm{c}$. in the batch were used to fabricate the first Australian-made teletherapy source, which was delivered to St. Vincent's Hospital, Sydney, during November 1961. The sales value of the 454 shipments of imported radioisotopes was $£ 14,400$ and the value of radioisotopos producod was $£ 12,646$. An order for 5,000 c. of cobalt-60 for delivery in 1962-3 was received from the Japan Radioisotope Association, and there are prospects of additional orders from Japan and countries in South-East Asia. The Radioisotope Advisory and Consulting Service of the Commission has carried out a number of interesting and important field and factory investigations using radioactive isotope techniques and these are described in some detail in the annual report.

In May 1962 the Minister for National Development announced that the Government had decided to continue uranium treatment operations at Rum Jungle after the completion of the Combined Development Agency contract. This decision was made in the light of the importance of Rum Jungle to the economy of the Northern 